\title{
Educação Especial e Projetos Pedagógicos Curriculares dos cursos de licenciaturas da Universidade Federal do Acre
}

\author{
Special Education and Curriculum Pedagogical Projects for Undergraduate \\ teaching courses at the Universidade Federal do Acre
}

\section{Educación Especial y Proyectos Pedagógicos Curriculares de los cursos de licenciaturas de la Universidad Federal de Acre}

Geisa Cristina Batista ${ }^{1}$

Professora mestra da Universidade Federal do Acre, Rio Branco, AC, Brasil e doutoranda na Universidade Federal de São Carlos, São Paulo, Brasil

E-mail: geisa.unir@gmail.com ORCID: https://orcid.org/0000-0002-0657-7252

\section{Marlene Rodrigues}

Professora doutora da Universidade Federal de Rondônia, Porto Velho, RO, Brasil

E-mail: marlene.rodrigues@unir.br ORCID: https://orcid.org/0000-0002-3030-6057

\section{Fátima Elisabeth Denari}

Professora doutora da Universidade Federal de São Carlos, São Carlos, SP, Brasil

E-mail: fadenari@terra.com.br ORCID: https://orcid.org/0000-0001-9248-6359

Recebido em 17 de abril de 2021

Aprovado em 02 de agosto de 2021

Publicado em 31 de agosto de 2021

\section{RESUMO}

Os Projetos Pedagógicos Curriculares das licenciaturas pressupõem formações inspiradas em concepções inclusivas, conforme a legislação vigente. Esta pesquisa objetivou analisar os projetos dos cursos de licenciaturas da Universidade Federal do Acre, quanto aos aspectos facilitadores da formação para 0 trabalho, com base nos pressupostos da Educação Especial. Seis projetos foram analisados, por meio de estudos descritivos e bibliográficos. Os resultados evidenciaram concepções e perspectivas de práticas inclusivas nos componentes curriculares, nas referências básicas e complementares, bem como nos estágios supervisionados, realizados após a formação em componentes curriculares de Fundamentos da Educação Especial e da Língua Brasileira de Sinais. A formação docente foi uma proposta advinda dessas análises, visando à incorporação dos pressupostos da Educação Especial às práticas educativas dos professores da Educação Superior. Os documentos legais que davam suporte a alterações nesse sentido datam de 2015. Entretanto, em 2019, o advento de alterações nas Diretrizes Curriculares Nacionais para a formação docente constitui um desafio para outras alterações nos projetos desses cursos.

Palavras-chave: Educação Especial; Projetos Pedagógicos Curriculares; Licenciaturas. 
http://dx.doi.org/10.5902/1984686X65323

\section{ABSTRACT}

The Curricular Pedagogical Projects of undergraduate courses presuppose training inspired by inclusive conceptions, in accordance with current legislation. This research aimed to analyze the projects of undergraduate courses at Universidade Federal do Acre, regarding the facilitating aspects of job training, based on the assumptions of Special Education. Six projects were analyzed, through descriptive and bibliographic studies. The results showed conceptions and perspectives of inclusive practices in the curricular components, in the basic and complementary references, as well as in the supervised internships, which are carried out after training in curricular components of Fundamentals of Special Education and Brazilian Sign Language. The teacher's training was a proposal arising from these analyzes, aiming at incorporating the assumptions of Special Education into the educational practices of higher education teachers. The legal documents that supported the changes in this regard date from 2015. However, in 2019, the advent of changes in the National Curriculum Guidelines for teacher training constitutes a challenge for other changes in the projects of these courses.

Keywords: Special Education; Curricular Pedagogical Projects; Undergraduate Teaching Courses.

\section{RESUMEN}

Los proyectos Pedagógicos Curriculares de las licenciaturas presuponen formaciones inspiradas en concepciones inclusivas, conforme la legislación vigente. Esta investigación objetivó analizar los proyectos de los cursos de licenciaturas de la Universidad Federal de Acre, cuanto a los aspectos facilitadores de la formación para el trabajo, con base en los presupuestos de la Educación Especial. Seis proyectos fueron analizados, a través de estudios descriptivos y bibliográficos. Los resultados evidenciaron concepciones y perspectivas de prácticas inclusivas en los componentes curriculares, en las referencias básicas y complementares, así como en las pasantías, que son realizadas después de la formación en componentes curriculares de Fundamentos de la Educación Especial y de la Lengua Brasileña de Señales. La formación docente fue una propuesta advenida de esos análisis, visando a la incorporación de los presupuestos de la Educación Especial a las prácticas educativas de los profesores de la Educación Superior. Los documentos legales que daban suporte a alteraciones en este sentido fechan de 2015. Sin embargo, en 2019, el advenimiento de alteraciones en la Directrices Curriculares Nacionales para la formación docente constituye un reto para otras alteraciones en los proyectos de esos cursos.

Palabras clave: Educación Especial; Proyectos Pedagógicos Curriculares; Licenciaturas.

\section{Introdução}

Determinadas alterações a práticas e condutas vigentes são propostas visando a uma sociedade mais justa, democrática, igualitária, equitativa e inclusiva. Esses mesmos valores devem ser incorporados às formações profissionais daqueles que serão os formadores da sociedade: os professores. Obviamente, essas incorporações constituem um processo 
http://dx.doi.org/10.5902/1984686X65323

lento, uma vez que, em suas formações, a maioria foi orientada por um modelo no qual não se configurava o contexto inclusivo escolar que atualmente é destaque nas ações e metas das políticas públicas. Mais do que um processo lento, trata-se, na verdade, de uma construção social e geracional. É possível esta observação, descrevendo a história cronológica da institucionalização da Educação Especial, no país.

Em 1973, o Ministério da Educação (MEC) criou o Centro Nacional de Educação Especial, o CENESP (BRASIL, 1973). O objetivo dessa iniciativa foi o de estimular a proposição de políticas públicas nacionais voltadas para a Educação Especial, fortalecendo o modelo assistencialista e, portanto, as instituições especializadas.

Mais tarde, a partir dos anos 1980, com as alterações propostas pela Constituição da República Federativa do Brasil de 1988, pela Lei de Diretrizes e Bases da Educação Nacional (LDBEN) o 9394 de 1996 e com o suporte técnico, financeiro e formativo para executar ações que ajudassem a estabelecer uma nova visão sobre o funcionamento da modalidade de Educação Especial, as propostas formativas das graduações ofertadas pelas Instituições Federais de Educação Superior (IFES) sofreram consideráveis alterações. Isso foi também fruto de projetos de pesquisas, de programas de extensão e de ações no campo do ensino.

Anos depois, o MEC emitiu a Portaria n.ำ1679, de 02 de dezembro de 1999 (BRASIL, 1999), que estabeleceu critérios de acessibilidade para a autorização dos cursos de Educação Superior no país, contemplando as necessidades das Pessoas com Deficiência $(P c D)$. No caso dos cursos de licenciaturas, que propiciam formações de profissionais para trabalharem desde a Educação Básica até a Educação Superior, houve especial urgência nas alterações materializadas, inicialmente, nos Projetos Pedagógicos Curriculares (PPC) das Instituições de Educação Superior (IES).

O Desenho Universal da Aprendizagem (DUA) já existia, embora estivesse sendo acessado paulatinamente no campo da Educação. No fundo, vinha sendo gestada a ideia de uma Educação para todos, independentemente de características fisiológicas, cognitivas e sociais. Tratava-se, em suma, de uma nova forma de conceber a aprendizagem, com base em uma abordagem acessível.

De acordo com a legislação brasileira vigente entre 2015 e 2019, os PPC dos cursos de licenciatura deveriam conter mecanismos para a garantia de princípios, na formação inicial, que consolidassem uma sociedade democrática e inclusiva. Acompanhando esses 
http://dx.doi.org/10.5902/1984686X65323

dispositivos legais, os conteúdos desses cursos deveriam incluir uma formação básica em Educação Especial e em Língua Brasileira de Sinais (Libras) (BRASIL, 2015).

Considerando todo esse contexto aqui brevemente esquematizado, esta pesquisa objetivou analisar os PPC dos cursos de licenciatura da Universidade Federal do Acre (UFAC) quanto aos aspectos que pudessem promover uma formação que ajudasse a construir uma sociedade inclusiva, com conteúdo da modalidade de Educação Especial. A tese de Rodrigues (2018) inspirou este trabalho, sendo tomada como referência. Entre outros procedimentos, a autora analisou os PPC dos cursos de licenciatura da Universidade Federal de Rondônia (Unir), com vistas a verificar a existência de indicadores de acessibilidade pedagógica e atitudinal na formação proposta, de forma a propiciar atendimento a estudantes da Educação Básica, público-alvo da Educação Especial.

Com base em uma perspectiva pedagógico-crítica, Rodrigues (2018) partiu da premissa de que não existe neutralidade no currículo. Trata-se de um documento que manifesta os interesses das instituições encarregadas da sua elaboração e manutenção. Portanto, o currículo reflete relações de poder imbricadas nessa elaboração. Há ainda um currículo oculto, no qual é possível identificar aspectos implícitos, que podem escapar a uma leitura desatenta e que não estão contidos no projeto oficial: indiferenças, preconceitos, discriminações, apatias e indignações, entre outros. Para além da análise documental dos PPC, Rodrigues (2018) promoveu um grupo focal com professores da área pedagógica dos cursos de licenciatura.

Sendo assim, o que se propôs neste trabalho foi uma adaptação dos procedimentos da tese de Rodrigues (2018). A partir de uma pesquisa documental, pretendeu-se analisar os PPC de seis cursos de licenciatura da UFAC, de modo a identificar conteúdos que pudessem contribuir para a construção de um currículo formativo que se mostrasse compromissado com a Educação Especial. Desse modo, foi analisado, especificamente, o currículo formal encontrado nesses PPC. A opção apenas por seis projetos se deu pelas respostas das coordenações dos cursos, aos e-mails enviados por uma das autoras. Apenas um dos projetos estava disponibilizado no repositório universitário, embora houvesse, na época, muitos outros cursos de licenciaturas.

É relevante ressaltar que a área pedagógica dos cursos de licenciaturas da UFAC é ministrada pelos mesmos professores lotados no Centro de Educação, Letras e Artes (CELA). Nesse sentido, embora não se fazendo presentes, os outros PPC foram construídos com a colaboração dos professores do CELA, no que tange à Fundamentos da 
http://dx.doi.org/10.5902/1984686X65323

Educação Especial, Fundamentos da Educação e Investigação e Práticas de Ensino e Estágio Supervisionado.

\section{Método}

Esta pesquisa foi conduzida nos moldes de um estudo descritivo, adaptando determinados procedimentos seguidos por Rodrigues (2018) - especialmente quanto ao objetivo geral e às categorias temáticas de análise. A proposta foi a de estabelecer relações entre as características de PPC da UFAC e os dispositivos sobre a Educação Especial encontrados nos documentos oficiais. Quanto aos procedimentos técnicos, optou-se pelos estudos bibliográficos (VILELAS, 2009), considerando materiais já publicados - ou seja, os PPC dos cursos de licenciatura.

No primeiro semestre do ano de 2019, encaminhou-se um e-mail às coordenações dos cursos de licenciatura da UFAC, solicitando os PPC desses cursos e informando o objetivo. As coordenações dos cursos de licenciatura em Ciências Biológicas, Letras/Libras, Letras/Inglês, Letras/Língua Portuguesa, Matemática e Química responderam prontamente à solicitação. Outras coordenações não responderam aos email-s e não sendo localizados no repositório institucional, os demais PPC foram excluídos desta análise. Compreende-se que pelo fato de uma das autoras ministrar aulas nesses cursos e manter contato, portanto, com tais coordenações, o acesso e a comunicação foram melhor efetivados e a solicitação prontamente atendida.

A partir da leitura desses projetos, buscou-se identificar elementos, nas Matrizes de Referências Curriculares, que remetessem ao comprometimento com a temática da inclusão escolar, especificamente da modalidade de Educação Especial: componentes curriculares, conteúdos, atividades de estágio, referências bibliográficas e oferta da Libras.

Devido a alterações recentes nas Diretrizes Curriculares Nacionais (DCN) para a formação de professores da Educação Superior, foram observados o ano de elaboração e a vigência dos PPC. A partir de 2015 e até 2019, com a aprovação da Resolução Federal n. 9 02/2015, os PPC deveriam incluir uma proposta formativa condizente com uma nova perspectiva de Educação escolar inclusiva, alicerçada nos preceitos da valorização da diversidade e contrária a toda forma de discriminação.

Sendo assim, pretendeu-se elucidar as seguintes questões sobre cada PCC analisado: a) o currículo prevê uma prática inclusiva?; b) os conteúdos abordados nos componentes curriculares contemplam o ensino e a aprendizagem do público-alvo da 
http://dx.doi.org/10.5902/1984686X65323

Educação Especial, quais sejam: $P c D$, Altas Habilidades/Superdotação (AHSD), Transtornos Globais do Desenvolvimento (TGD) e Transtorno do Espectro Autista (TEA)?; c) há a exigência de uma postura de acessibilidade pedagógica e atitudinal por parte do formando?

Adotando-se os mesmos procedimentos de Rodrigues (2018), foram estabelecidas quatro categorias de análise. São elas: categoria 1 - concepções do curso; categoria 2 componentes curriculares que abordam a temática da Educação Inclusiva; categoria 3 componentes curriculares que poderiam abordar a temática da Educação Inclusiva; e categoria 4 - indicativos de acessibilidade pedagógica, atitudinal, arquitetônica e comunicacional. $O$ quadro 1 , a seguir, apresenta as siglas utilizadas para a referência a cada PPC ao longo deste trabalho.

Quadro 1 - Siglas de identificação dos PPC

\begin{tabular}{|l|c|}
\hline PROJETOS PEDAGÓGICOS CURRICULARES (PPC) & SIGLA \\
\hline PPC da Licenciatura em Ciências Biológicas & C1 \\
\hline PPC da Licenciatura em Letras/Inglês & C2 \\
\hline PPC da Licenciatura em Letras/Libras & C3 \\
\hline PPC da Licenciatura em Letras/Língua Portuguesa & C4 \\
\hline PPC da Licenciatura em Matemática & C5 \\
\hline PPC da Licenciatura em Química & C6 \\
\hline
\end{tabular}

Fonte: Elaborado pelas autoras (2020).

\section{Resultados e discussão}

Segundo Sacristán (2013), o currículo é a estrutura da cultura contida nos conteúdos que são ensinados. Concebe-se, criticamente, que o currículo tem sido uma ferramenta regulatória das práticas educativas e do conhecimento, sintetizando tanto este último como a cultura (ARROYO, 2015).

As práticas educativas que acontecem no trabalho e nas ações coletivas dos movimentos sociais pressionam as instâncias de poder para que determinados aspectos sejam incorporados ao currículo e, portanto, conhecidos tanto pelos professores quanto pelos estudantes (ARROYO, 2015). Nos processos de formação inicial, os futuros licenciados precisam conhecer o teor de alterações que ocorrem no domínio da prática profissional. Promover mudanças implica lutar para que sejam comtempladas as aspirações desses movimentos sociais representativos de grupos que buscam o fortalecimento por meio de processos coletivos emancipatórios. 
http://dx.doi.org/10.5902/1984686X65323

A Resolução n. 02/2015, que até 2019, definiu as Diretrizes Curriculares Nacionais (DCN) para a formação inicial em nível superior e para a formação continuada, abordou as mudanças provocadas por grupos representativos, os quais lutam por inclusão social, com base no respeito às diferenças. Essa resolução enfatizou a intenção de construir uma sociedade democrática, justa, soberana e inclusiva e que tivesse como princípios a promoção da "emancipação dos indivíduos e grupos sociais, atenta ao reconhecimento e à valorização da diversidade e, portanto, contrária a toda a forma de discriminação" (BRASIL, 2015, p. 4). Aos egressos dos cursos de licenciaturas, caberia consolidar a inclusão escolar, por meio do respeito às diferenças e do reconhecimento e da valorização "da diversidade étnico-racial, de gênero, sexual, religiosa, de faixa geracional, entre outras" (BRASIL, 2015, p. 6).

Vale frisar que, com a exceção do curso C3, que tinha uma reformulação tramitando processualmente nas instâncias da UFAC, todos os outros PPC foram concebidos a partir da Resolução n.. 02/2015. Além disso, cada Núcleo Docente Estruturante (NDE) dos seis cursos considerados, teve liberdade, de acordo com suas atribuições, de opinar sobre a concepção e a construção dos projetos curriculares - obviamente, considerando as DNC dos respectivos cursos.

É válido ressaltar, que a Resolução n.ำ 2/2019 (BRASIL, 2020a), republicada com alterações em 2020 no Diário Oficial da União (DOU), apresenta outros princípios basilares educacionais. Além disso, uma nova Política Nacional de Educação Especial foi publicada nesse mesmo ano (BRASIL, 2020). Sabe-se, no entanto, que esse último documento foi suspenso pelo Supremo Tribunal Federal (STF, 2020), devido ao entendimento de que o seu teor pode fragilizar o direito à inclusão já garantido constitucionalmente às PcD.

Em seguida, apresentam-se as análises dos PPC dos cursos de licenciatura da UFAC, nas quais se buscou identificar as intenções do ensino e, por conseguinte, da formação docente que se pretendia proporcionar à Educação Básica do estado do Acre no momento da elaboração dos documentos aqui considerados. Nessas análises, procurou-se identificar ainda a presença de referências que dessem sustentação às intenções, às concepções e aos componentes curriculares.

\section{Concepções do curso}

Analisando-se o teor das concepções de "Educação" que cada PPC adotou, observouse que a proposta da Educação Inclusiva esteve presente. Quando isso não aconteceu 
http://dx.doi.org/10.5902/1984686X65323

explicitamente, apresentou-se tal proposta sob a forma de uma abertura para a discussão de temas e de problemas sociais.

Dos seis cursos analisados, três explicitaram a expressão "Educação Inclusiva" na abordagem da concepção do curso (C1, C3 e C6); um (C2) apresentou uma concepção dialética, de base crítica, voltada para a desconstrução de determinadas concepções, incluindo temas pós-coloniais, que analisam os efeitos políticos, filosóficos e literários, dentre outros, deixados pelos países colonizadores, que podem produzir sequelas culturais; o C5 apresentou um panorama com base em uma competência política que dá autonomia ao professor para fazer as suas escolhas.

Tanto C5 quanto C4 teorizaram as concepções em suas áreas específicas, aludindo à linguagem como produção da cultura humana e ao inconformismo com o fracasso escolar na área de atuação. Tal abordagem pode ser considerada como afim à da Educação Especial. Além disso, C6 abordou a "Educação Científica como promotora da inclusão social". Segundo esse PPC, havendo oportunidades de pesquisas, será possível promover os conhecimentos relativos à inclusão escolar. C3 foi mais específico, ao citar a Convenção da Organização das Nações Unidas Sobre os Direitos da Pessoa com Deficiência, o Plano Nacional da Pessoa com Deficiência e a Perspectiva de Educação Inclusiva adotada pelo MEC.

\section{Componentes curriculares que abordam a temática da Educação Inclusiva}

Todos os PPC analisados apresentaram o componente curricular Fundamentos da Educação Especial, o que permite afirmar que, em todos os cursos, foram incluídas noções básicas sobre a modalidade em questão. Além disso, nos seis projetos, esse componente deveria ser ofertado no semestre anterior ao estágio supervisionado. Essa constitui uma boa decisão, uma vez que, desse modo, o primeiro contato com estudantes da Educação Especial acontece depois de um estudo dos conhecimentos elementares sobre essa modalidade de ensino.

$\mathrm{Na}$ análise dos componentes curriculares, observou-se temas diversificados. Educação Especial e Educação Inclusiva constaram em todas as referências básicas. C1, C3, C4 e C6 fizeram referências explícitas a AHSD; C5 mencionou o "estímulo ao desenvolvimento de múltiplas inteligências". Quanto ao atendimento a estudantes que apresentam TEA ou TGD, somente o curso C2 fez referência a essa problemática. C1 mencionou as dificuldades de aprendizagem relacionadas a condutas típicas. 
http://dx.doi.org/10.5902/1984686X65323

Em relação ao atendimento a diferentes deficiências, a deficiência intelectual (DI) e a deficiência mental (DM) foram referidas por C2 e C5; a deficiência física, incluindo questões motoras, por C2; a deficiência visual, por C2 e C5; a deficiência auditiva ou o estudante surdo, por C1, C2, C4, C5 e C6. A deficiência múltipla (DMu), a surdocegueira e a dupla excepcionalidade não foram referidas.

Por um lado, os projetos referiram aspectos como atendimento a estudantes com necessidades educacionais/educativas especiais, práticas inclusivas, formação de professores para esse atendimento, acesso e permanência desse público, políticas públicas, histórico da Educação Especial, rompimento de barreiras para a aprendizagem, entre outros. Por outro lado, a existência de determinadas referências básicas possibilitaria o acesso a conhecimentos mais específicos. É evidente que não se pode concluir que não se promoverá a aprendizagem dessa ou daquela condição humana, apenas porque o PPC não contemplou determinado tópico. Entende-se que o próprio momento da aula pode provocar diversas discussões. Contudo, nesta pesquisa, não se identificou, de forma clara e objetiva, a intenção de conduzir os licenciandos à aprendizagem de conhecimentos mais específicos. Portanto, não se pode afirmar que determinado PPC previu a discussão do assunto. Os tópicos foram incluídos no geral e não no específico, no caso daqueles projetos que não discriminaram referências pontuais a determinada condição humana.

Algumas novidades foram identificadas. Como componente curricular optativo, o curso C4 disponibilizou 60 horas teóricas de Braille, mas não incluiu referências básicas. Os componentes optativos foram inseridos a partir do $3 .^{\circ}$ semestre. Desse modo, caso 0 componente Braille fosse ofertado, a aprendizagem poderia ocorrer antes ou durante 0 estágio supervisionado. Com base no "Guia Braille para Língua Portuguesa", disponibilizado pelo MEC, esta pode ser considerada uma oportunidade formativa que enriquece o currículo.

Como optativa, o curso C5 ofertou o componente Tecnologia Assistiva e Práticas Inclusivas e a (Re)construção da Prática Pedagógica no Ensino-aprendizagem de Matemática (Deficiência Visual/Intelectual). A disciplina foi concebida para ser ministrada de forma presencial, com o uso de computadores e em Ambiente Virtual de Aprendizagem (AVA)/Moodle.

O curso C6 incluiu o componente Práticas de Instrumentação para o ensino de Química na Educação Especial e atribui-Ihe 45 horas-aula, divididas entre carga horária em teórica e prática. Essa carga horária inclui o ensino e a aprendizagem de conteúdos de 
http://dx.doi.org/10.5902/1984686X65323

Química para o 1. , 2. e 3. anos do Ensino Médio, confecções de materiais, recursos e estratégias didáticas, produções e adaptações de materiais didáticos e instrumentos de avaliações para o atendimento a estudantes deficientes. Não houve referências específicas ao atendimento às necessidades especiais, apenas referências de práticas de ensino e ensino de Química. Entretanto, foram sugeridas microaulas, ciclos de seminários e minicursos, como atividades e uso de artigos acadêmicos disponibilizados em periódicos da área. Logicamente, isso tudo pode promover relatos de experiências sobre a Educação Especial.

Observou-se que os componentes curriculares optativos que se diferenciaram de um curso para o outro ocorreram devido à experiência ou qualificação profissional de determinados docentes.

O curso C6 apresentou componente específico de práticas de ensino para a Educação Especial, contando com a Grafia Química Braille para Uso no Brasil, produzida pelo MEC, que atende a estudantes e profissionais da Educação Básica e Superior. Em C3, a presença do Braille surpreendeu. Esse foi o único curso a incluir esse componente. O NDE desse curso acompanhou as publicações do MEC quanto às práticas inclusivas e incluiu a grafia Braille para a Língua Portuguesa e as normas técnicas para produção de textos nesse sistema de escrita (BRASIL, 2018).

O MEC disponibiliza livros em Braille para a Educação Básica e conta com uma comissão específica para acompanhar e atualizar o uso e aplicação do Sistema Braille no Brasil, em todas as áreas do conhecimento. Essas informações constam no site oficial do ministério e dão suporte aos componentes curriculares dos cursos C3 e C6. Tais cursos poderiam servir de exemplo para outras licenciaturas, considerando-se a existência desse público-alvo (cegos/ baixa visão) nos vários níveis da Educação Básica. Embora existam aplicativos que viabilizem a comunicação para pessoas com deficiência visual, o Sistema Braille é um sistema de língua/linguagem que não se modifica - o que se alteram são as tecnologias, os softwares.

Quanto ao componente curricular Libras, que constava como outra das exigências da Resolução ․ $^{\circ}$ 02/2015, os projetos C1, C2, C3 e C5 reservaram, das 60 horas contidas em todos os cursos analisados, 20 horas para aulas práticas. Já os cursos C4 e C6 disponibilizaram somente aulas teóricas. O C3, por habilitar em Letras/Libras, optou por seis fases de 60 horas-aula cada. A disciplina é ofertada no mesmo semestre em que ocorre 
http://dx.doi.org/10.5902/1984686X65323

o estágio supervisionado, o que pode gerar mais oportunidades de uso dessa língua em situações escolares.

\section{Componentes curriculares que poderiam abordar a temática da Educação Inclusiva}

Discussões sobre "normal versus fisiológico" e "anormal versus patológico" podem despertar a produção de conhecimentos relativos às condições do público-alvo da Educação Especial. O curso C1 incluiu componentes curriculares com potencial para isso. Destacaram-se as disciplinas de Fisiologia Humana (75 horas) e Anatomia Humana (60 horas).

Segundo Canguilhem (2009, p. 19), a "distinção entre o normal e o fisiológico e o anormal ou patológico seria [...] uma simples distinção quantitativa, se nos prendêssemos aos termos excesso e falta". Uma pessoa pode gozar de perfeita saúde e ter alguma deficiência. A representação social de que essa pessoa com deficiência teria necessariamente alguma patologia poderia ser eliminada. Nas concepções de C1, a Educação Científica poderia contribuir para a aquisição de conhecimentos da modalidade Educação Especial.

O componente Educação e Sociedade (60h) foi incluído no primeiro semestre de todos os cursos. É oportuno evocar o questionamento de Apple (2017): a Educação teria poder para mudar a sociedade? Quando se pensa na Educação institucionalizada como mediadora da existência histórica, principalmente no que concerne à prática política, que trata do envolvimento e de interações sociais, as escolas podem desafiar as hierarquias que dominam a sociedade. Conectar o espaço escolar com as comunidades oprimidas e organizar esse espaço sob os princípios de solidariedade podem conduzir à emancipação dos sujeitos (APPLE, 2017). Sendo assim, as discussões promovidas nas aulas de Educação e Sociedade podem provocar alterações na visão de mundo dos estudantes.

O componente Estágio Supervisionado, ofertado após as aulas de Fundamentos da Educação Especial e concomitantemente às aulas de Libras, poderia contemplar experiências da Educação Básica com estudantes da Educação Especial, inserindo os licenciandos no planejamento, por meio de livros didáticos apropriados para as pessoas com deficiência visual, por exemplo. Os contatos com materiais didáticos adaptados nas Salas de Recursos Multifuncionais (SRM) para estudantes com baixa-visão servem como outro exemplo. Além disso, outra possibilidade de significativa relevância acadêmica seria a flexibilização curricular para a aprendizagem e para a avaliação de estudantes com DI, 
http://dx.doi.org/10.5902/1984686X65323

com estudos de casos reais existentes nas escolas. Elaborar materiais de Comunicação Alternativa e Aumentativa (CAA) para estudantes com Encefalopatia Crônica Não Evolutiva/Progressiva (ECNP) - Deficiência Física (DF), propiciando a interação, no processo de aprendizagem, entre esses estudantes seriam outras atividades propiciadoras de novas experimentações no processo formativo docente. Defende-se, portanto, que dependendo das condições facilitadoras ofertadas, o estágio supervisionado poderia facilitar o acesso às experiências da modalidade de Educação Especial, considerando os professores responsáveis pela condução desse processo e as situações vivenciadas nas escolas.

O componente Sexualidade e Desenvolvimento Humano apareceu no curso C1. Desmitificar que a PcD cresce e se desenvolve cognitivamente, fisicamente, fisiologicamente, com todos os hormônios que uma pessoa sem deficiência apresenta, seria uma possiblidade de abordagem para essa disciplina. Frequentemente, ocorre de os familiares, não sabendo como lidar com esse processo de desenvolvimento humano da PcD, infantilizem o convívio com esses indivíduos, mesmo com os já adultos. Obviamente, referências básicas deveriam constar nos planos de cursos, mesmo que de forma complementar.

As Atividades Acadêmico-Científico-Culturais (AACC), que perfazem 200 horas, são distribuídas entre participações em iniciação à docência, pesquisas, cursos, palestra, eventos científicos, entre outras possibilidades. Fazer de tais atividades uma oportunidade para o contato com temas da Educação Inclusiva depende, essencialmente, dos próprios licenciandos. Há potencial para a inclusão de atividades sobre essa modalidade educacional, mas a escolha seria do próprio acadêmico - ou seja, essas 200 horas não são necessariamente destinadas à Educação Especial.

O componente Seminário de Humanidades, de 60 horas, faz parte do projeto do curso C2. Com dois créditos teóricos e um prático, a disciplina visa as atividades sobre Educação e Direitos Humanos e a formação para a cidadania. São tratados temas como escola e violência, jovens em cumprimento de medidas socioeducativas, direito à escola, discriminação na escola, em relação a aspectos étnico-raciais, religião, orientação sexual e de gênero, com projetos inter e transdisciplinares. Quando das interações sociais dentro da escola, o estudante poderia proceder a um levantamento de questões sociais que merecem reflexão. Seria possível inserir as vivências dos estudantes da Educação 
Especial? Haveria possibilidade, desde que houvesse uma observação particular das situações no interior das relações estabelecidas entre tais estudantes.

O componente Psicologia da Educação foi incluído nos cursos de licenciatura analisados. A disciplina poderia contribuir para o ensino da Educação Especial, desde que inserissem referências bibliográficas complementares que pudessem tratar das questões da aprendizagem e do desenvolvimento humano do público-alvo dessa modalidade. Não foram encontradas tais referências. Constava Vigotski, mas não as Obras Escogidas do autor, as quais apresentam conteúdos específicos de como tratar estudantes surdos e da área de DI e Deficiência Visual (DV). Quando se dá sentido às experiências de todas as crianças, inclusive das que apresentam diferenças fisiológicas, anatômicas e cognitivas, o ensino fica mais inclusivo.

O filme A maçã (La pomme, de 1998), de Samira Makhmalbaf, retrata a intervenção de uma assistente social no destino de duas crianças. O longa-metragem pode ser articulado às discussões de Vygotski (1997) a respeito das formas coletivas de colaboração em formas individuais de condutas - trata-se das Funções Psicológicas Superiores (FPS). A trama retrata, ao longo de três meses, a história de duas irmãs que são mantidas aprisionadas em casa. A história ocorre no Irã, sob forte influência da religião islâmica. Nesse contexto, o pai, a princípio, julga estar sendo injustiçado pela comunidade local, devido às denúncias dos vizinhos e à exposição do caso de suas filhas nas mídias sociais. Quando o Estado, por meio de uma assistente social, intervém nesse caso, as crianças dão início às aventuras que lhes permitirão interagir socialmente, ocasionando um desenvolvimento cultural compensatório.

As ações empreendidas pelas profissionais no caso das crianças do filme demonstram que os pressupostos de Vygotski são promissores quando utilizados pedagogicamente. No caso dessa família, havia o detalhe de a mãe viver em situação de DV. Entretanto, a questão mais importante não está nesse aspecto, mas na inexistência de interação social entre os pares familiares e a ausência de convívio com outros grupos sociais - isso contribuiu para uma ausência de desenvolvimento da linguagem pelas crianças.

Conclui-se, portanto, que há uma relação entre a colaboração coletiva e o desenvolvimento das FPS, ou desenvolvimento cognitivo; basta dar sentido à experiência vivida, pois, em Vigotski (2008; 2009), o pensamento é um modo de reelaboração dessa experiência. 
http://dx.doi.org/10.5902/1984686X65323

O componente curricular Investigação e Práticas Pedagógicas foi identificado em todos os cursos, mas ele poderia ser flexibilizado. Obviamente, isso dependeria da inserção de referências bibliográficas apropriadas. Compreende-se que a maioria dos componentes teria condições de colaborar mais para a construção dos saberes sobre a modalidade educacional em questão. Os professores da área de formação pedagógica poderiam ser inseridos em programas específicos, com o objetivo de incentivar esses profissionais a investirem em práticas educativas que atendessem aos aspectos inclusivos que os estudantes da Educação Especial requerem.

O componente Tecnologias da Comunicação e da Informação foi incluído no curso C5. O objetivo da disciplina seria familiarizar os alunos com aplicativos matemáticos voltados para o ensino. Nesse contexto, existem tecnologias digitais de acessibilidade para todos os tipos de demandas. Santarosa (2010) apresenta uma infinidade de softwares e hardwares como recursos da área multidisciplinar de TA. Ampliar os conhecimentos nessa temática demandaria alterar também as referências básicas e/ou complementares.

O mesmo curso (C5) disponibilizou, como componente curricular optativo, conteúdos sobre TA. Trata-se de um curso de extensão universitária que foi idealizado pela professora que o ofertava. Ela tem doutorado na área. No caso específico dessa licenciatura, esse componente apresentava-se com quatro créditos teóricos (60 horas). É importante notar que a formação dessa docente contribuiu para a concretização dessa ação particular no curso.

Ainda sobre a área da TA, o curso C3 apresentou, em suas referências, o Sistema SignWriting, a escrita funcional para o surdo. Trata-se de uma iniciativa do curso de Letras/Libras, mas que poderia estar inserida em todos os outros cursos, de modo a usar outras tecnologias que facilitassem toda a forma de CAA.

O componente Linguagem, gênero e sexualidade, de abordagem teórica, foi incluído no curso C3. A disciplina aborda a cultura surda, mas poderia dar ênfase a outras condições humanas também. Esse tema é pouco tratado nas escolas da Educação Básica por questões variadas. Devido a um certo fundamentalismo religioso e ao racismo biológico, são propostos modelos dicotômicos para a constituição identitária.

As Infecções Sexualmente Transmissíveis (IST), a gravidez precoce, o aborto e as constituições de identidade sexual genética, social e psicológica são realidades com crescimento estatístico de atendimento nas unidades de Saúde Pública. Isso poderia 
http://dx.doi.org/10.5902/1984686X65323

despertar o coletivo para a necessidade de uma sociedade mais consciente, não somente nas abordagens teóricas, mas na prática e na vivência política.

Desse modo, defende-se que esse tema - o da sexualidade - seja tratado como componente curricular de outros cursos de licenciatura. O público-alvo das escolas de Educação Básica inclui crianças e adolescentes. Abusos sexuais podem estar acontecendo no contexto familiar desses estudantes, e as escolas poderiam colaborar para a denúncia e proteção desse público vulnerável.

O componente Organização Curricular e Gestão da escola, de 60 horas, foi incluído em todas as licenciaturas. Se a organização curricular e o modelo de gestão escolar estivessem pautados pela inclusão dos estudantes da Educação Especial, a visão do licenciando sobre essa temática poderia ser alterada, desenvolvendo, com profissionalismo, as competências necessárias para a adoção de postura política com base em um DUA.

O componente Culturas e identidades contemporâneas (45 horas), oferecido no curso C2, também pode proporcionar uma discussão sobre as maiorias minorizadas sociais que se encontram nas escolas. Entre elas, está incluído o público-alvo da Educação Especial.

\section{Indicativos de acessibilidade pedagógica, atitudinal, arquitetônica e comunicacional}

Inter-relacionando-se as possibilidades que se apresentaram nos componentes específicos da Educação Especial e aqueles que poderiam discutir questões ligadas a essa modalidade de ensino - considerando, porém, que ainda não foram encontradas referências básicas ou complementares para tanto - as competências que foram estabelecidas para os egressos concordavam com o modelo inclusivo. Em seguida, para cada curso, comentam-se as razões que fundamentam tal afirmação.

No curso C1, identificou-se um compromisso com a construção de uma sociedade mais justa e igualitária, que superasse as exclusões sociais. O egresso, segundo o respectivo PPC, deve demonstrar consciência da diversidade, respeitar as diferenças de diversas naturezas, inclusive, as de necessidades especiais, e, ainda, compreender a legislação educacional para o exercício do magistério.

O curso C2 privilegiou o estágio supervisionado do 7.9 semestre para as diversas modalidades de ensino, inclusive a Educação Especial. No estágio subsequente, o foco foi para a elaboração de materiais didáticos. Nessa segunda fase, com os conhecimentos atinentes à modalidade de Educação Especial, os materiais poderiam também ser 
http://dx.doi.org/10.5902/1984686X65323

elaborados com TA de baixo custo, caso as investigações ocorressem com o intuito de suprir as necessidades, quando existentes. A curricularização da extensão, que é um projeto que visa a incorporação das atividades de extensão, prevista na Lei $n .$. 13.005/2014, que aprovou o Plano Nacional de Educação (PNE), observa que 10\% da carga horária de cursos de graduação deve estar voltada para projetos de "grande pertinência social". Podese pensar em temas que incluam as pessoas com todas as suas diferenças e especificidades, com base em um DUA.

O curso C3 propôs que o egresso fosse capaz de dominar novas tecnologias, o que faria com que ele estivesse em constante busca por atualizações dos softwares e de hardwares que dão autonomia e funcionalidade às pessoas que delas necessitam. As TA devem ser usadas não somente pelos estudantes surdos, mas por todos. As questões da cegueira e da baixa visão poderiam ser ampliadas durante o processo de formação docente.

O curso C4 estabeleceu três competências básicas para os egressos, as quais colaborariam para uma formação na perspectiva inclusiva: 1) ter percepção de diferentes contextos interculturais; 2) utilizar diferentes recursos tecnológicos; e 3) dominar métodos e técnicas pedagógicas que permitam a transposição dos conhecimentos para os diferentes níveis e modalidades de ensino. Essa proposta amplia as possibilidades de atendimento à demanda da Educação Especial, especialmente no que diz respeito às questões da $T A, e$ reflete $o$ entendimento de que o futuro professor deve estar preparado para intervir em diferentes contextos interculturais, inclusive nessa proposta de perceber as diferenças e os diferentes - ou seja, os grupos heterogêneos, sempre em uma perspectiva de que a diferença é individual e está em todos os estudantes.

O curso C5 estabeleceu uma articulação entre cinco eixos para a concepção de seu currículo - o uso da TA foi um deles, além dos conhecimentos essenciais das teorias da aprendizagem e do desenvolvimento cognitivo. Isso evidencia uma proposta que se coaduna com a perspectiva de aprofundar temas específicos das diferenças, tanto na aprendizagem quanto nos outros processos importantes para a promoção do desenvolvimento cognitivo. O uso das TA, como recursos, estratégias e símbolos, poderia colaborar para uma proposta realmente inclusiva. Obviamente, as referências complementares deveriam ser incluídas.

O curso C6 propôs a identificação dos aspectos filosóficos e sociais que definem a realidade social. O licenciado deve: ser sensível a toda forma de comunicação; desenvolver 
http://dx.doi.org/10.5902/1984686X65323

a capacidade de preparar e desenvolver recursos didáticos; contribuir para o processo de humanização no seu local de trabalho; conscientizar-se do papel do professor na sociedade; articular os conhecimentos específicos de seu curso com as tecnologias e as Ciências Humanas e Sociais; refletir sobre a sua própria prática; identificar problemas de ensino e de aprendizagem; e comprometer-se com a profissão em todas as esferas escolares. Compreende-se que essas competências possibilitariam interferências, no ambiente escolar, de modo a propiciar condições para o atendimento às necessidades específicas dos estudantes amparados pela Educação Especial.

Quanto às referências bibliográficas, básicas e complementares, que constam nos projetos, observou-se que, para o curso de Libras, foram mobilizados autores clássicos, que poderiam colaborar para a construção de boas bases conceituais durante as aulas. Em relação à carga horária de 60 horas atribuída à disciplina homônima, é importante frisar que, nesse tempo, é apenas possível aprender as bases da língua em questão. Por meio de cursos de extensões, essa aprendizagem pode ser expandida, apresentando ao aluno a Libras Intermediária, Avançada, etc. Esses cursos podem consolidar e aprofundar os conhecimentos advindos da carga horária inicial.

Quanto às AHSD, foram identificadas referências específicas em C1 e C3. C4 e C5 incluíram referências para as múltiplas inteligências. No curso C6, observaram-se variadas referências sobre práticas inclusivas, o que pode contemplar orientações para as AHSD. Contudo, não consta, especificamente, essa expressão nas referências.

O curso C2 referiu as expressões "deficiências motoras" e "ajudas técnicas" para o ensino da DF. Compreende-se que as questões motoras estão relacionadas à ECNP ou à Paralisia Cerebral, que está incluída no campo das DF. O curso C1 também apresentou referências.

O curso C3 somente apresentou propostas para as AHSD e para os surdos, além das referências gerais à Educação Inclusiva, sem, contudo, especificar condições. O PPC em questão foi elaborado em 2014 - ou seja, trata-se de um documento anterior à Resolução n. $\stackrel{0}{0}$ 02/2015.

Para o atendimento a estudantes com DI (ou mental), apenas os cursos C2 e C5 incluíram referências. Esses cursos foram os que fizeram referências mais explícitas ao atendimento a estudantes com DV, embora o curso C4 tenha apresentado uma proposta de oferta de componente curricular para o Braille, e o C6, para práticas de ensino para DV. 
http://dx.doi.org/10.5902/1984686X65323

Os TGD e os TEA foram mencionados somente pelo curso C2. Esse detalhe é importante porque as estatísticas têm demonstrado um aumento de estudantes com TEA na Educação Básica. Nesse sentido, é importante para os licenciandos conhecerem esse público específico.

A DMu não foi mencionada nas referências de nenhum dos cursos. A dupla excepcionalidade (MASSUDA; RANGNI, 2017) também não constou. O fato de serem raras as avaliações que resultam em diagnósticos de tais condições pode ajudar a explicar o porquê de elas não receberem mais atenção na Educação Superior.

Analisando-se os títulos das referências básicas e complementares dos PPC dos cursos de licenciatura considerados, verificou-se que algumas propostas apresentaram respaldo bibliográfico para a formação docente na perspectiva do atendimento a estudantes da Educação Especial, especificando práticas para determinadas condições humanas, enquanto outras referências são mais abrangentes, pensadas sob uma perspectiva de modelo escolar inclusivo. Não se pode afirmar que, em tais documentos, constem obras voltadas para uma formação a atendimentos a cada especificidade da modalidade analisada.

\section{Considerações finais}

Nesta pesquisa, observou-se que os PPC analisados, de forma geral, incorporaram conteúdo e práticas inclusivas, o que reflete uma forte preocupação com o atendimento à legislação, bem como, indica que esses cursos de licenciatura conceberam a construção de uma sociedade inclusiva, que respeita as diferenças.

Notou-se que o componente curricular Fundamentos da Educação Especial foi incluído em todos os PPC, o que indica que esse público-alvo seria referenciado durante as aulas. As referências básicas e complementares se reportaram às necessidades educacionais especiais, contemplando o tema em questão. Compreende-se, no entanto, que a aprendizagem pode não ocorrer, a despeito de disponibilização dessas referências básicas. Notou-se que algumas condições humanas foram referidas com maior frequência, tanto nos conteúdos quanto nas referências.

Quanto à exigência de uma postura de acessibilidade pedagógica e atitudinal por parte dos formandos, no perfil do egresso, foi possível identificar tal exigência. De modo geral, os cursos privilegiaram com condições de buscar recursos e estratégias pedagógicas que pudessem incluir pessoas, indistintamente de suas características peculiares, dando atenção às questões identificadas nas diferenças individuais. 
Quanto às referências básicas e complementares, quando se comparou um projeto com outro, observou-se que cada qual apresentou referências sobre inclusão escolar, mas que alguns privilegiaram questões específicas da Educação Especial, com destaque para as AHSD, que foi mencionada em quase todos os projetos. Entretanto, não se identificou uma preocupação com pessoas em situação de DMu e de dupla excepcionalidade. Ainda nas referências, foram incipientes as propostas para o TEA e para estudantes surdos, limitando-se à oferta de um curso de Libras.

Outras referências básicas e complementares poderiam ser incluídas para garantir que os docentes da Educação Superior discutissem problemáticas mais específicas em suas aulas, incorporando os desdobramentos dos movimentos sociais que lutam pela promoção da equidade - não só nos ambientes sociais, mas também nos acadêmicos

Uma ação que os cursos de licenciaturas, especialmente os das IFES, poderiam incluir seria a qualificação dos professores universitários, para garantir o cumprimento dos dispositivos legais e assegurar a promoção, em tese, da Resolução n.․ 02/2015 quanto à Educação Inclusiva, mesmo que essa resolução tenha sido revogada pela Resolução CNE/CP n.․ 2/2019 (BRASIL, 2020a). Essa formação promoveria, em tese, a acessibilidade pedagógica, atitudinal e comunicacional, por parte do professor, para com o público-alvo da modalidade em questão () (pessoas com: deficiência, transtornos globais do desenvolvimento, transtorno do espectro autista e altas habilidades/superdotação). Esses profissionais teriam oportunidades de repensar e alterar as suas práticas educativas na direção daquilo que os documentos legais defendem: uma sociedade inclusiva, que inclua os seus diferentes com equidade. Poderiam ainda ser incorporados conteúdo e referências complementares nos PPC.

As referências à Educação Inclusiva que foram identificadas nos PPC dos cursos de licenciatura da UFAC sinalizam o comprometimento de propor um modelo formativo inicial com vistas à formação de uma sociedade com conhecimentos ampliados na compreensão da equidade, mesmo que esse processo estivesse em sua fase inicial. Isso pode estar comprometido, haja vista a necessidade de todas as IFES repensarem seus PPC para atenderem a uma nova demanda apresentada tanto no Parecer n.. 22/2019 (BRASIL, 2019), quanto na Resolução n.ำ 2/2019 (BRASIL, 2020a).

Propõe-se futuras pesquisas em PPC de cursos de licenciaturas que tenham sido reformulados com base na nova proposta da Resolução n 2/2019. 
http://dx.doi.org/10.5902/1984686X65323

\section{Referências}

APPLE, M. A educação pode mudar a sociedade? Petrópolis, RJ: Vozes, 2017.

ARROYO, M. G. Os Movimentos Sociais e a construção de outros currículos. Educar em Revista, Curitiba, n. 55, Editora UFPR, p. 47-68, jan./mar. 2015. Disponível em: https://bit.ly/3txvHmm. Acesso em: 28 fev. 2021.

BRASIL, Presidência da República. Decreto n.. 72.425, de 03 de julho de 1973. Cria o Centro Nacional de Educação Especial (Cenesp), e dá outras providências. Diário Oficial da União, Brasília, 04 jul. 1973. Disponível em: https://bit.ly/3vEGZHI. Acesso em: 28 fev. 2021.

BRASIL. Ministério da Educação. Conselho Nacional de Educação. Conselho Pleno. Parecer CNE/CP n.․ 22/2019. Diretrizes Curriculares Nacionais para a Formação Inicial de Professores para a Educação Básica e Base Nacional Comum para a Formação Inicial de Professores da Educação Básica (BNC-Formação). Diário Oficial da União, Brasília, 20 dez. 2019. Disponível em: https://bit.ly/3eL7fKi. Acesso em: 13 out. 2020.

BRASIL. Ministério da Educação. Conselho Nacional de Educação. Resolução CNE/CP n. $-2 / 2015$, de 09 de junho de 2015. Institui Diretrizes Curriculares Nacionais para a formação inicial em nível superior (cursos de licenciatura, cursos de formação pedagógica para graduados e cursos de segunda licenciatura) e para a formação continuada. Diário Oficial da União, Brasília, 02 jul. 2015. Disponível em: https://bit.ly/2QfQOvk. Acesso em: 13 out. 2020.

BRASIL. Ministério da Educação. Conselho Nacional de Educação. Resolução CNE/CP n. $-2 / 2019$, de 20 de dezembro de 2019. Define as Diretrizes Curriculares Nacionais para a Formação Inicial de Professores para a Educação Básica e institui a Base Nacional Comum para a Formação Inicial de Professores da Educação Básica (BNC-Formação). Diário Oficial da União, Brasília, 15 abr. 2020a. Disponível em: https://bit.ly/3tv6xVB. Acesso em: 25 jun. 2020.

BRASIL. Ministério da Educação. Portaria n.ำ 1679/1999, de 02 de dezembro de 1999. Dispõe sobre requisitos de acessibilidade de pessoas portadoras de deficiências, para instruir os processos de autorização e de reconhecimento de cursos, e de credenciamento de instituições. Diário Oficial da União, Brasília, 03 dez. 1999. Disponível em: https://bit.ly/3ł3HEwr. Acesso em: 28 fev. 2021.

BRASIL. Ministério da Educação. Secretaria de Educação Continuada, Alfabetização, Diversidade e Inclusão. Grafia Braille para a Língua Portuguesa. 3. ed. Mistério da Educação: Brasília, 2018.

BRASIL. Presidência da República. Decreto n.. 10.502/2020, de 30 de setembro de 2020. Institui a Política Nacional de Educação Especial: Equitativa, Inclusiva e com Aprendizado ao Longo da Vida. Diário Oficial da União, Brasília, 01 out. 2020b. Disponível em: https://bit.ly/3bWosOS. Acesso em: 13 out. 2020. 
BRASIL. Presidência da República. Lei n.ำ12.764/2012, de 27 de dezembro de 2012. Institui a Política Nacional de Proteção dos Direitos da Pessoa com Transtorno do Espectro Autista; e altera o $\S 3 .^{\circ}$ do art. 98 da Lei $n .^{\circ}$ 8.112, de 11 de dezembro de 1990. Diário Oficial da União, Brasília, 28 dez. 2012. Disponível em: https://bit.ly/2QhLgjW. Acesso em: 28 fev. 2021.

BRASIL. Presidência da República. Lei n. 13.005/2014, de 25 de junho de 2014. Aprova o Plano Nacional de Educação - PNE e dá outras providências. Diário Oficial da União, Brasília, 26 jun. 2014. Disponível em: https://bit.ly/3tr3uO0. Acesso em: 28 fev. 2021.

CANGUILHEM, G. O normal e o patológico. 6. ed. rev. Rio de Janeiro: Forense Universitária, 2009.

LA Pomme. Direção: Samira Makhmalbaf. Intérpretes: Massoumeh Naderi, Ghorban Ali Naderi, Zahra Naderi e Azizeh Mohamadi. Roteiro: Mohsen Makhmalbaf e Samira Makhmalbaf. Irã, França e Holanda: Hubert Bals Fund, MK2 Productions, Makhmalbaf Productions e Rotterdam Film Festival, 1998. 1 DVD (86 min.), widescreen, color.

RANGNI, R. de A.; MASSUDA, M. B.; COSTA, M. da P. R. da. Altas habilidades/superdotação: temas para pesquisa e discussão. São Carlos: EdUFSCar, 2017.

RODRIGUES, M. Formação Docente para Inclusão de Estudantes Público-Alvo da Educação Especial em Cursos de Licenciaturas da Universidade Federal de Rondônia. 2018. 343 f. Tese (Doutorado em Educação Escolar) - Universidade Estadual Paulista "Júlio de Mesquita Filho", Araraquara, 2018. Disponível em: https://bit.ly/3tzVVEK. Acesso em: 17 mar. 2021.

SACRISTAN, J. G. (org.). Saberes e incertezas sobre o currículo. Porto Alegre: Penso, 2013.

SANTAROSA, L. M. C. (org.) Tecnologias Digitais Acessíveis. Porto Alegre: JSM Comunicação, 2010.

SUPREMO TRIBUNAL FEDERAL (STF). Suspensa eficácia do decreto que instituiu a política nacional de educação especial. Ação Direta de Inconstitucionalidade (ADI) 6590. Notícias STF, 01 dez. 2020. Disponível em: https://bit.ly/30SUQf7. Acesso em: 28 fev. 2021.

VILELAS, J. Investigação - O Processo de Construção do Conhecimento. Lisboa: Ed. Sílabo, 2009.

VYGOTSKI, L. S. Obras Escogidas v Fundamentos de Defectología. Volumen CXXIX de la Colección Aprendizaje. Editorial Pedagógica, Moscú, 1983. De la presente edición VISOR DIS., S.A., 1997.

VYGOTSKY, L. S. A Formação Social da Mente: o desenvolvimento dos processos psicológicos superiores. 7. ed. São Paulo: Martins Fontes, 2009.

VYGOTSKY, L. S. Pensamento e Linguagem. 4. ed. São Paulo: Martins Fontes, 2008. 


\section{Notas}

${ }^{1}$ Bolsista CNPq.

\section{(c) (i) (9)} International (CC BY-NC 4.0) 